\title{
TRUST AND CONTROL IN THE CONTEXT OF INTEGRATED PROJECT DELIVERY
}

\author{
Lena Frantz', Anna Hanau², Maximilian R.-D. Budau ${ }^{3}$, Shervin Haghsheno ${ }^{4}$, \\ Cornelius Väth ${ }^{5}$, and Jan-Simon Schmidt ${ }^{6}$
}

\begin{abstract}
Project delivery models with a high level of integration of the involved partners like "Project Alliancing" (e.g. in Australia and Finland) and "Integrated Project Delivery" (IPD) (e.g. in the US and Canada) have been used successfully for many years. These models differ from traditional models particularly by integrating key project participants at an early stage and offer incentive models based on the success of the project. In this article the term "Integrated Project Delivery" (IPD) is also used as a generic term for project delivery models with a high level of integration.

The successful implementation of these models requires a high degree of trust between the partners. At the same time a certain level of control can be beneficial or even required. The following article examines the question which elements in an IPD project influence the level of trust between the partners and to what extent control is required in turn. Therefore elements of IPD that require trust are identified and their configuration depending on the level of trust is analysed.
\end{abstract}

\section{KEYWORDS}

Trust, control, integrated project delivery, IPD.

\section{INTRODUCTION}

"Integrated Project Delivery" (IPD) has been used successfully worldwide for many years. This project delivery model differs from traditional models in particular by the early integration of key project participants, incentive models geared to project success, and increased use of lean methods. (AIA California Council 2014) In the meantime, this approach is also being applied in pilot projects in Germany. Due to the lack of experience with this approach in Germany, among other things the role of trust and control within these projects have not yet been conclusively defined. Trust is the prerequisite for

1 Research assistant, Civil and Envir. Engrg. Dept., Karlsruhe Institute of Technology, lena.frantz@kit.edu, orcid.org/0000-0003-0199-5399

2 Project manager, Väth \& Schmidt, ㅌfo@vaeth-schmidt.de, +49 711 / 49004-337, orcid.org/0000$\underline{0001-8438-9057}$

3 Research assistant, Civil and Envir. Engrg. Dept., Karlsruhe Institute of Technology, maximilian.budau@kit.edu, orcid.org/0000-0002-2572-1176

4 Professor, Civil and Envir. Engrg. Dept., Director, Karlsruhe Institute of Technology, shervin.haghsheno@kit.edu, orcid.org/0000-0002-0602-6370

5 Managing Director, Väth \& Schmidt, info@ vaeth-schmidt.de, +49 711 / 49004-337, orcid.org/00000001-8416-9206

$6 \quad$ Managing Director, Väth \& Schmidt, info@vaeth-schmidt.de, +49 711 / 49004-337, orcid.org/0000$\underline{0002-3537-6396}$ 
collaborative teamwork and is seen as a success factor for projects (Schön 2020a). The factors that influence trust between project participants and the relationship between control tasks and trust are not yet clearly known.

Within the framework of a research project, the authors investigated which roles are necessary for successful project execution and how much control is appropriate or permissible for this success by the respective roles. It was thus investigated by which elements the degree of trust between the partners in an IPD project is influenced and to what extent control is required.

In the following, first results of this research project are presented. For this purpose, in the first step the terms trust and control are discussed. In the next step a framework is developed to explain the releationship between trust and control. This framework serves as the basis for the further research. Finally the relationship between trust and control is exemplified by discussion of three selected trust issues and control tasks.

\section{THEORETICAL BACKGROUND}

\section{TRUST}

There is no universally valid and unambiguous definition for the term trust. (Schön 2020a p. 34, b pp. 1-3) The term trust is defined differently depending on the scientific field, such as psychology, sociology and economics. Different definitions of trust are presented below and finally a definition relevant for this research is derived. However, this article does not contain a fully comprehensive discussion of the term trust.

Duden (2021) describes trust as a firm conviction of the reliability of a person or thing. According to Rousseau et al. (1998), trust is a psychological state that involves the intention to accept vulnerability, based on positive expectations about another's intentions or behavior. (Rousseau et al. 1998) Schön (2020a p. 43) defines trust as follows: Trust is the confidence that another person will act predictably in the common interest.

The various definitions show that trust represents a positive expectation (Duden 2021; Mayer et al. 1995a; Rousseau et al. 1998; Schön 2020a) of the future and can build up between a person (Trustor) and one or more other persons or a thing (Trustee). Moreover, some definitions imply that trust involves risk in the form of a breach of trust (Mayer et al. 1995a; Petermann 2013; Rousseau et al. 1998).

Based on this in this article trust is defined as follows:

"Trust is the positive expectation from a person, organization, or system with confidence that they will behave predictably in the common interest and do not pursue their personal interest."

Depending on whether trust arises in relation to one person, several persons or a system, a distinction can be made between the two types of "personal trust", referred to below as ,individual trust“", and "system trust". (Luhmann 2014; Schön 2020a p. 44)

Individual trust" refers to the perception and interaction of two actors. The individual trust of the trustor is formed on the one hand by the perception of the personally conditioned actions of the trustee as well as by the repeated fulfillment of the given trust. Thereby, the more often trust has been confirmed, the higher is the individual trust. (Luhmann 2014 p. $47 \mathrm{ff}$ ) The trustor thereby gives less "effort" at the beginning (with previously unconfirmed trust) and thus risks less damage through an abuse of trust (Luhmann 2014 p. 56).

Luhmann (2014 p. $60 \mathrm{ff})$ describes "system trust" as trust in the functioning of systems. Everyday examples of system trust are people's trust in the value and function 
of money as a medium for transactions and trust in science. In system trust, a person relies on a system having enough control to ensure the system's functioning and thus forgoes further information and performance reviews (Luhmann 2014 pp. 27, 69). System trust also develops through ongoing experience in using the system. However, unlike personal trust, system trust degrades less through individual disappointments. (Luhmann 2014 p. 64,75; Wong et al. 2008)

The establishment of trust depends on various further factors: lived experiences with the trustee (Kramer 1999; Luhmann 2014; Mayer et al. 1995b; Müthel 2006); reputation (Kenning 2002; cf. Kramer 1999 pp. 576-577), skills, goodwill, integrity (Mayer et al. 1995 b p. 715), commitment, organizational culture of the trustee (Walker and Rowlinson 2020) and the willingness to trust and risk-taking of the trustor (Müller 2019). The presence of trust can in turn have a positive impact on the project. For example, trust has a positive effect on the working atmosphere in the team and on the team's performance (Edmondson 1999; Lindskold 1978). It therefore makes sense to establish a certain level of trust for the sake of the project outcome.

\section{CONTROL}

The term control is also viewed and defined differently in the literature. Das and Teng define control as a process of regulating and monitoring to achieve organizational goals (Das and Teng 2001 p. 258). Green and Welsh (1988) define that control is always goaldirected and thus regulates a system so that the system fulfills a conscious or unconscious purpose. (Green and Ann Welsh 1988 pp. 298-291) Consequently, control can be understood as the process of monitoring and achieving organizational goals, as well as the outcome in terms of power and domination over one or more persons or a thing.

Das and Teng (1998, p. 501) distinguish between formal and social control. The main difference between these two elements is that formal control is an evaluation of performance, while social control refers to the way people are treated. Here, formal control uses specific rules, objectives, procedures, and regulations to monitor and promote desired performance. Formal control can thereby control either processes (behavioral control) or specific outcomes or performance goals (output control). The implication of formal control is that stakeholders cannot make fully autonomous decisions. In this context, inappropriate formal control in particular is negatively related to trust. (Das and Teng, 1998, p. 501,2001, p. 259) Social control relies on normative considerations to influence the behavior of others. Social control induces desired behavior through "soft" measures, such as interactions and training. The influence here takes the form of shared goals, values, and norms. Social control requires more trust and mutual respect because there is no direct constraint on the behavior of the participannts. Thus, in social control, a certain level of trust in the abilities and competence of the participants is necessary. (Das and Teng, 1998, p. 502)

In addition, control can be divided into the elements "control mechanisms" and "control level". Control mechanisms describe the organizational arrangements that determine and influence the behavior of organizational members and serve to increase the predictability of the achievement of certain goals. The level of control is the direct result of the control process, i.e. the degree to which one believes that the correct behavior of the other party is ensured. Because control mechanisms increase the predictability of goals, when used effectively, they can help generating trust. (Das and Teng, 1998, p. 493)

In the literature, there is no prevailing opinion regarding possible interactions between the elements of trust and control. On the one hand, a complementary relationship between 
trust and control is assumed. On the other hand, it is assumed that trust and control are not mutually exclusive, but can also exist simultaneously. (Das and Teng 2001)

\section{InTEgrated Project Delivery}

According to Lahdenperä, the origins of "integrated project delivery" can be traced back to the oil industry in the 1990s. (Lahdenperä 2012) There, offshore projects were successfully managed through the formation of a project alliance. These successes led to the introduction and increasing application of these approaches in the Australian construction market, particularly in the infrastructure sector, under the name "project alliancing". (Schlabach 2013)

Another approach, called IPD, was first mentioned in the USA in the early 2000s (Lahdenperä 2012). IPD and "project alliancing" are also called collaborative delivery methods. Trust, in turn, is the foundation for collaborative and cooperative work (Engeb $\varnothing$ et al. 2019 p. 779; Schöttle et al. 2014 p. 1271; Zhang and Qian 2016 p. 1889). True collaboration enables project teams to accomplish challenging tasks (Hartman 2000; Robbins and Judge 2011; Smith et al. 2014). Trust leads to effective communication (cf. Hartman 2000) and information sharing between the people in a project (cf. Robbins and Judge 2011).

\section{OVERVIEW OF THE INVESTIGATION}

\section{FRAMEWORK}

The framework presented in Figure 1 serves as the basis for the investigations. The framework was derived from theoretical considerations on trust and control (see above) based on a literature review and was validated with the help of expert interviews. A total of 77 references were analyzed and four people with experience in IPD and Alliance projects were interviewed. The keywords of the research were combinations of the terms: Trust, Control and IPD.

The framework divides trust into two types: "individual trust" and "system trust". Both types of trust are state variables, which can change in the course of an IPD project. At the beginning of an IPD project (at time $t=0$ ) there is an initial trust between the individuals or organizations and in IPD as a system. The initial trust is based on perceived or experienced trustworthiness. Over the course of an IPD project, both types of trust can then increase or decrease depending on the external influences as well as the control tasks. Trust can thus be seen as a varying state variable, which can increase as well as decrease depending on experience.

In the context of this article, a control task comprises, on the one hand, the verification of a person or organization, e.g. in the form of a check of claimed or assumed and real states. On the other hand, a control task includes the comparison of planned and realized variables. The degree of control (high or low) or by whom the control task is performed depends on the respective trust level (individual and system trust) and external requirements. The interactions between the level of trust and the degree of control are presented in the following chapters. 


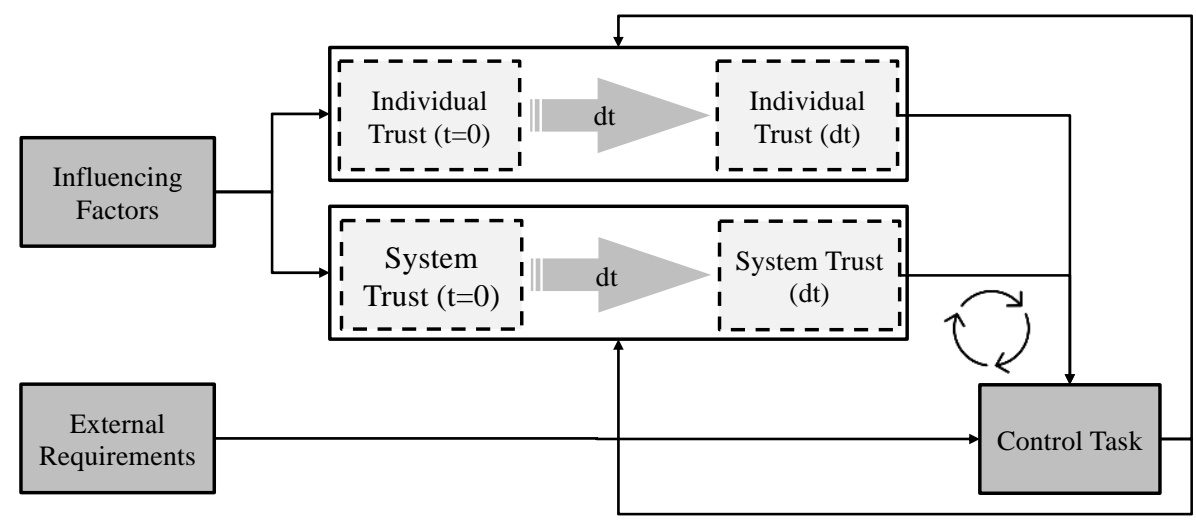

Figure 1: Framework for illustrating the interactions between trust and control

\section{IDENTIFICATION OF TRUST ISSUES AND INTERDEPENDENCIES}

The methodological approach for identifying control tasks and the trust issues and their interactions in the context of integrated project delivery is presented below. A comprehensive literature review and evaluation was conducted to identify possible control tasks in the context of integrated project delivery. Different types of literature, such as contracts, guidance documents, case studies, and general literature, were evaluated and possible control tasks were extracted. The literature review was conducted using a keyword search. This was followed by the development of trust issues. Trust issues are subject areas in which trust and control are relevant. Either the current level of trust has an impact on a trust issue or the way it is structured has an impact on it. The following chapter will explicitly deal with three selected trust issues listed in Table 1.

Table 1: Selected trust issues

\begin{tabular}{|c|c|}
\hline Key word & Description \\
\hline Team Selection & $\begin{array}{l}\text { Participation in an IPD project requires, in addition to specific } \\
\text { capabilities, special soft skills to maintain good cooperation and } \\
\text { collaboration and to create innovative solutions. A special care } \\
\text { must be taken when selecting participants to ensure that the parties } \\
\text { coming into the project have the qualities and skills necessary for } \\
\text { an IPD project. }\end{array}$ \\
\hline $\begin{array}{l}\text { Definition of Target } \\
\text { Costs }\end{array}$ & $\begin{array}{c}\text { Establishing the target costs is an important point in the course of } \\
\text { the project. Since the partners' remuneration depends on this, the } \\
\text { partners must be able to trust that each partner has calculated its } \\
\text { costs in accordance with the specifications and is not pursuing any } \\
\text { self-interest. }\end{array}$ \\
\hline $\begin{array}{c}\text { Remuneration of IPD } \\
\text { Partners }\end{array}$ & $\begin{array}{l}\text { Remuneration under IPD is essentially based on the costs incurred } \\
\text { by the individual partners. Here, trust is important in several } \\
\text { respects. For example, transparency is necessary and the } \\
\text { disclosure of cost parameters requires trust. }\end{array}$ \\
\hline
\end{tabular}

In addition to the trust issues identified in Table 1 the following issues were also identified: Insurance Program, Contracting, Shared Decision Making, Conflict Resolution, Managing Teams, Performance Management, Company Metrics, Opportunity and Risk, Collaboration, Establishing and Sustaining Team Culture, IPD Experience.

Building on the compilation of trust issues and control tasks in the context of IPD, the various effect relationships according to the framework presented between the degree of 
trust and the design of the control task were investigated and recommendations for actions were derived based on the authors' experience and, where necessary, validated and supplemented with results from the literature and the expert interviews. The results are presented below exemplified for the trust issues mentioned in Table 1. According to the expert surveys, these aspects represent neuralgic points in the course of an IPD project.

\section{SELECTED TRUST ISSUES AND CONTROL TASKS IN IPD PROJECTS}

\section{Team Selection}

In contrast to traditional construction projects, the selection of participants in IPD is not only based on commercial criteria and the technical skills of the applicants. There is usually a comprehensive process in which the applicants are evaluated according to defined criteria. The criteria include commercial criteria and technical ability as well as necessary soft skills and collaborative skills. (Allison et al. 2020 pp. 30-33; Department of Infrastructure and Regional Development 2015a p. 68; Macdonald and Sc 2011 p. 216f; Pishdad-Bozorgi and Beliveau 2016 p. 158; Schlabach 2013 p. 105f).

In this task, control can be adjusted by checking more or less criteria. In addition, the selection process can be conducted either through one or more interviews or through an assessment center. This control task can increase the system trust, because beside commercial criteria also further abilities of the applicants are examined. The interviews also confirm that individual trust can be increased because the project participants get to know each other earlier in a comprehensive selection process and the project participants can assume that the partners for the IPD project are capable and can work collaboratively.

Additional consultants may be brought in, to monitor the legitimate conduct of the selection process, to verify the commercial and technical procedure and performance of the applicants, and to verify their capabilities to work collaborativly. These other control tasks can additionally increase system trust by ensuring the fairness of the selection process and allowing partners to assume applicant ability and suitability for the IPD project. Due to the interaction between system trust and individual trust, system trust can positively transfer to individual trust to a certain extent.

Some applicants attend training prior to the selection process on the skills required for IPD. This shows commitment and motivation and can increase individual trust. These and other relationships and their effects on trust are shown schematically in Figure 2. 


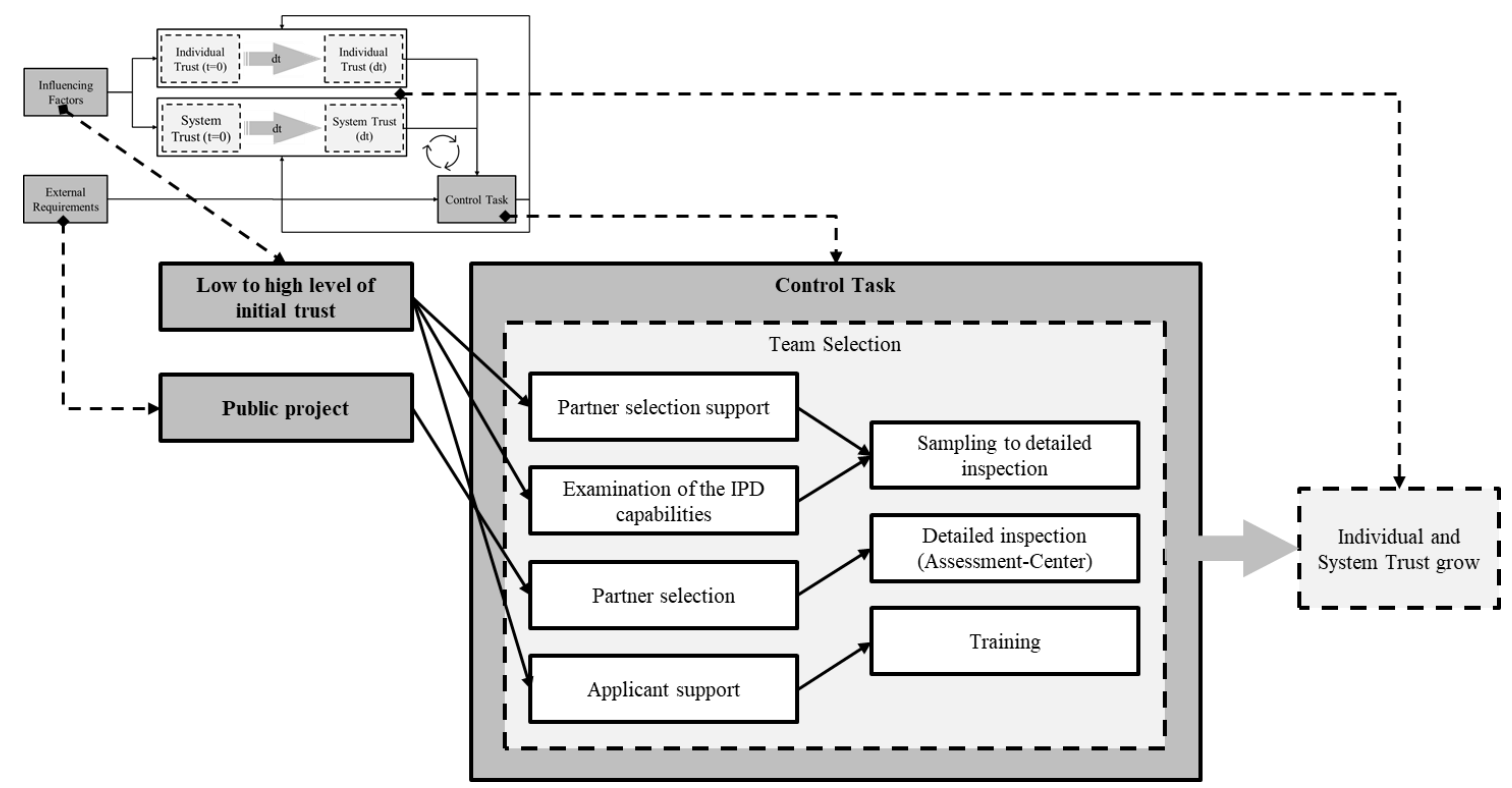

Figure 2: Trust issue "Team Selection"

\section{DEFINITION OF TARGET COSTS}

The process of defining the target costs requires a high degree of cooperation. However, this is usually not sufficient to obtain an economical target cost. For this, there must also be sufficient technical expertise in the project. (Walker 2016) In addition, the use of external consultants is also sometimes recommended, either to review the cost estimation that has been carried out (Department of Infrastructure and Regional Development 2015b) or to develop a further cost estimate (Macdonald 2011). The conducted interviews indicated that performing these two tasks is often recommended regardless of the level of trust. This is particularly recommended for public projects (Department of Infrastructure and Regional Development 2015b). Regardless of the reason for performing these inspection tasks, the interviews showed that performing them usually increases the level of trust.

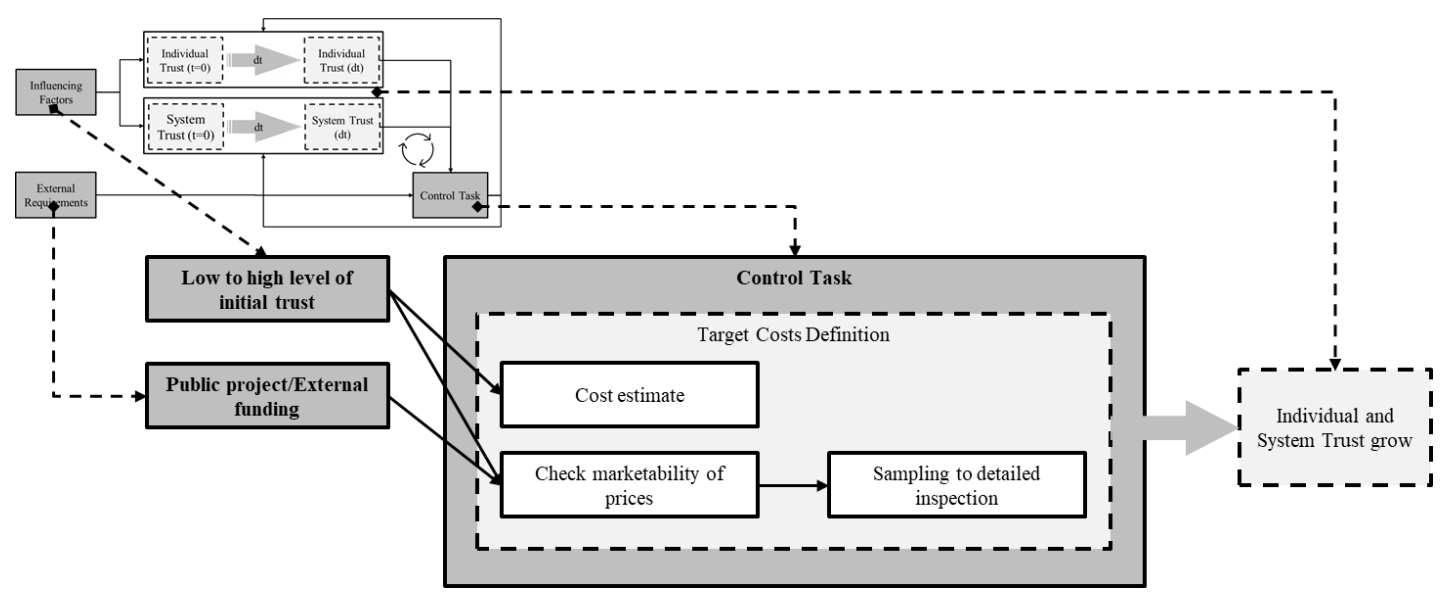

Figure 3: Trust issue "Target Costs Definition"

\section{REMUNERATION OF IPD PARTNERS}

Remuneration under IPD is essentially based on the costs incurred by the individual partners. A high level of transparency is important. The resulting control tasks are necessary project tasks but their design depends on the level of trust. As one of the control 
tasks audits reveal the accrued costs which will be refunded and therefore allow fair fees for the team members. Here an audit can vary regarding its intensity, e.g. it is possible to just do a plausibility check, if the level of trust is really high, or on the contrary to verify every detail, if the level of trust is quite low. Knowing that there are the same regulations for every participant increases the system trust. Whereas successful checks without mistakes also increase the individual trust.

Another task is the review of accounting and calculation either through the IPD team or through an external auditor. This decision does not only depend on the level of trust but also on the competence and capacity of the IPD team. Partly participants will be in favour of a third party as not every team member gets a detailed look into their accounting this way. These rules will also lead to a growth of the individual and system trust because the participants know that the other parties are acting as promised.

Another control task is the continuous cost tracking which includes a comparison between the target and the actual costs. This monitoring enables the team to be aware of deviations at a very early stage so that they can find solutions together and therefore improve. Furthermore this task confirms the capability of the team and strengthens them in their collaborative behaviour.

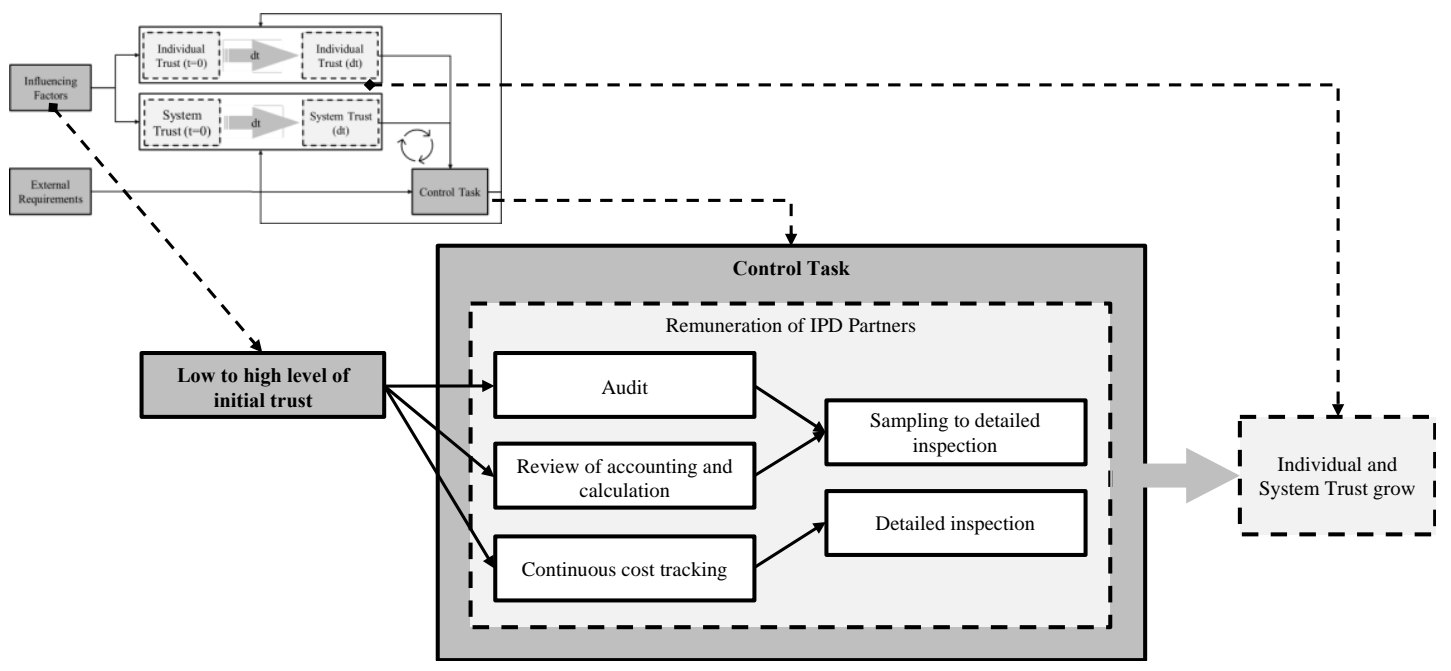

Figure 4: Trust issue "Remuneration of IPD Partners"

\section{CONCLUSIONS}

This article discussed the relevance of trust and control in the context of IPD. A distinction must be made here between trust between the participants and trust in the system. However, so-called control tasks are also required for the system to function. These control tasks interact with the different types of trust in the project. On the basis of so-called trust issues it was shown that the execution of one of these control tasks can also increase the trust level. However, this does not mean that there is a direct correlation between trust and control. Project execution is a very complex system in the context of which control tasks can have very divergent effects on trust in the project. This interplay was shown by focusing on three trust issues.

This article contains parts of the results of a research project. This project has not yet been completed. But even beyond this project, the interplay between trust and control must be further investigated in order to increase the understanding of IPD and thus further improve acceptance and project performance. 


\section{REFERENCES}

AIA California Council. (2014). "Integrated Project Delivery : an Updated." American Institute of Architects, 1-18.

Allison, M., Ashcraft, H., Cheng, R., Klawans, S., and Pease, J. (2020). Integrierte Projektabwicklung Ein Leitfaden für Führungskräfte Deutsche Übersetzung.

Das, T. K., and Teng, B. S. (2001). "Trust, control, and risk in strategic alliances: An integrated framework." Organization Studies, Walter de Gruyter and Co., 22(2), 251283.

Department of Infrastructure and Regional Development. (2015a). National Alliance Contracting Guidelines - Guide to Alliance Contracting.

Department of Infrastructure and Regional Development. (2015b). National Alliance Contracting Guidelines - Template 1 - Project Alliance Agreement.

Duden | Vertrauen. (2021). "Duden | Vertrauen | Rechtschreibung, Bedeutung, Definition, Herkunft." https://www.duden.de/rechtschreibung/Vertrauen (Jan. 20, 2021).

Edmondson, A. (1999). "Psychological safety and learning behavior in work teams." Administrative Science Quarterly, 44(2), 350-383.

Engebø, A., Skatvedt, A., and Torp, O. (2019). "Soft elements in collaborative project delivery methods." 27th Annual Conference of the International Group for Lean Construction, IGLC 2019, The International Group for Lean Construction, 773-784.

Green, S. G., and Ann Welsh, M. (1988). Cybernetics and Dependence: Reframing the Control Concept. Source: The Academy of Management Review.

Hartman, F. T. (2000). "The role of TRUST in project management." PMI® Research Conference 2000, Project Management Institute, Paris, France.

Kenning, P. (2002). Customer Trust Management. Customer Trust Management, Deutscher Universitätsverlag.

Kramer, R. M. (1999). TRUST AND DISTRUST IN ORGANIZATIONS: Emerging Perspectives, Enduring Questions. Annu. Rev. Psychol.

Lindskold, S. (1978). "Trust development, the GRIT proposal, and the effects of conciliatory acts on conflict and cooperation." Psychological Bulletin, 85(4), 772793.

Luhmann, N. (2014). Vertrauen. UVK Verlagsgesellschaft mbH, Konstanz.

Macdonald, C. C. (2011). "Value for Money in Project Alliances".

Mayer, R. C., Davis, J. H., and David Schoorman, F. (1995a). An Integrative Model of Organizational Trust.

Mayer, R. C., Davis, J. H., and Schoorman, F. D. (1995b). "An Integrative Model of Organizational Trust." The Academy of Management Review, The Academy of Management, 20(3), 709-734.

Müller, M. (2019). Vertrauen durch Transparenz. Vertrauen durch Transparenz, Springer Fachmedien Wiesbaden.

Müthel, M. (2006). "Erfolgreiche Teamarbeit in deutsch-chinesischen Projekten." Entscheidungs- und Organisationstheorie, Deutscher Universitäts-Verlag/GWV Fachverlage GmbH, Wiesbaden.

Petermann, F. (2013). Psychologie des Vertrauens. Göttingen.

Pishdad-Bozorgi, P., and Beliveau, Y. J. (2016). "A Schema of Trust Building Attributes and Their Corresponding Integrated Project Delivery Traits." International Journal of Construction Education and Research, Routledge, 12(2), 142-160.

Robbins, S. P., and Judge, T. A. (2011). Essentials of Organizational Behavior. Prentice Hall. 
Rousseau, D. M., Sitkin, S. B., Burt, R. S., and Camerer, C. (1998). "Not so different after all: A cross-discipline view of trust." Academy of Management Review.

Schlabach, C. (2013). "Untersuchungen zum Transfer der australischen Projektabwicklungsform Project Alliancing auf den deutschen Hochbaumarkt.” Kassel University Press.

Schön, W. (2020a). Vertrauen, die Führungsstrategie der Zukunft. Vertrauen, die Führungsstrategie der Zukunft, Springer Berlin Heidelberg.

Schön, W. (2020b). Vertrauensorientiertes Projektmanagement Top-10-Erfolgsfaktoren für Projekte und Veränderungsprozesse. Springer Gabler, Wiesbaden.

Schöttle, A., Haghsheno, S., and Gehbauer, F. (2014). "Defining Cooperation and Collaboration in the Context of Lean Construction." IGLC-22, Oslo, 1269-1280.

Smith, J. P., Rybkowski, Z. K., Bergman, M., and Shepley, M. (2014). "Trust-builder: A first-run study on active trust-building." 22nd Annual Conference of the International Group for Lean Construction: Understanding and Improving Project Based Production, IGLC 2014, 305-316.

Walker, D. H. T., and Rowlinson, S. (2020). Routledge Handbook of Integrated Project Delivery. Routledge Taylor \& Francis Group, London, New York.

Walker, D., and Lloyd-Walker, B. M. (2016). "Understanding the Alliance Target Outturn Cost Process and its Implications." (September).

Wong, W. K., Cheung, S. O., Yiu, T. W., and Pang, H. Y. (2008). "A framework for trust in construction contracting." International Journal of Project Management, 26(8), 821-829.

Zhang, L., and Qian, Q. (2016). "Exploring the Factors for Collaborative Relationships in IPD Projects." Construction Research Congress, ASCE, 1886-1896. 